\title{
Parental Self-Efficacy-A Predictor of Children's Health Behaviors? Its Impact on Children's Physical Activity and Screen Media Use and Potential Interaction Effect Within a Health Promotion Program
}

\author{
Katrin Kieslinger ${ }^{1}$, Olivia Wartha ${ }^{2}$, Olga Pollatos ${ }^{1}$, Jürgen M. Steinacker ${ }^{2}$ and \\ Susanne Kobel ${ }^{2 *}$ \\ ${ }^{1}$ Department Clinical and Health Psychology, Institute of Psychology and Education, Ulm University, Ulm, Germany, ${ }^{2}$ Division \\ of Sports and Rehabilitation Medicine, Centre of Medicine, Ulm University Hospital, Ulm, Germany
}

OPEN ACCESS

Edited by:

Efrat Neter

Ruppin Academic Center, Israel

Reviewed by:

Monika Boberska,

SWPS University of Social Sciences

and Humanities, Poland

Hagen Wulff,

Leipzig University, Germany

Ofra Walter,

Tel-Hai College, Israel

*Correspondence:

Susanne Kobel

susanne.kobel@uni-ulm.de

Specialty section:

This article was submitted to

Health Psychology,

a section of the journal

Frontiers in Psychology

Received: 21 May 2021

Accepted: 19 July 2021

Published: 12 August 2021

Citation:

Kieslinger K, Wartha O, Pollatos O, Steinacker JM and Kobel S (2021) Parental Self-Efficacy - A Predictor of

Children's Health Behaviors? Its Impact on Children's Physical Activity and Screen Media Use and Potential

Interaction Effect Within a Health

Promotion Program.

Front. Psychol. 12:712796.

doi: 10.3389/fpsyg.2021.712796
Insufficient physical activity (PA) and increased screen media use (SMU) can have detrimental effects on children's health. Parental self-efficacy (PSE) can act as an important predictor for a healthy upbringing. The aim of this study was to investigate the influence of PSE on children's PA and SMU. Additionally, a moderating effect of PSE on the intervention effect of the health promotion program "Join the Healthy Boat" was examined. Using a prospective randomized controlled trial, 558 kindergarten children (3.6 years $[S D=0.6]$ ) were examined. Data was collected using parental self-report. A significant influence of PSE on children's PA $(B=0.33, p=0.025)$ and children's SMU $(B=0.42, p=0.006)$ was found. The moderating effect of PSE on the intervention effect was neither significantly related to children's PA $(p=0.360)$ nor to children's SMU $(p=0.531)$. This confirms the importance of PSE on children's health development. Despite the lack of a moderating effect, interventions should also promote healthy activity behaviors and self-efficacy for parents in order to engage children in a healthy lifestyle.

Keywords: parental self-efficacy, physical activity, parents, media use, screen time, prevention, kindergarten children

\section{INTRODUCTION}

High prevalence of overweight and obesity pose a worldwide health risk for children and adolescents and subsequently across their lifespan (Skinner et al., 2015; Abarca-Gómez et al., 2017; GBD 2015 Obesity Collaborators, 2017; Sagar and Gupta, 2018; Garrido-Miguel et al., 2019). In 1975, worldwide, five million girls and six million boys aged 5-18 were overweight (Abarca-Gómez et al., 2017). In 2016, 41 years later, more than 50 million girls and 74 million boys reached an overweight or obese status (Abarca-Gómez et al., 2017). A prospective study showed that $90 \%$ of children who were obese at an age of 3 years were also overweight or obese as adolescents (Geserick et al., 2018). Furthermore, a simulation showed that obesity in adulthood can be predicted by an early development of obesity (Ward et al., 2017). This highlights the importance of taking preventive measures against obesity, particularly in early years, since childhood overweight and obesity increase the likelihood of developing other diseases such as diabetes, coronary heart disease or cancer in adulthood (Llewellyn et al., 2016). 
Promoting healthy physical activity and screen media use is one way to reduce the number of overweight children (Katzmarzyk et al., 2015; Ling et al., 2016; Kobes et al., 2018). Both the trend toward less physical activity and increasing digitalization already have an impact on children's health (Medienpädagogischer Forschungsverbund Südwest, 2014, 2018; Domingues-Montanari, 2017; Finger et al., 2018). Sufficient physical activity and time-controlled screen media use are important factors, which affect a healthy development of children into adulthood (Saunders and Vallance, 2017; Biddle et al., 2019).

The World Health Organization (WHO), which defines physical activity as any "movement of the body that uses energy over and above resting" recommends a minimum of $180 \mathrm{~min}$ of daily physical activity at any intensity with at least $60 \mathrm{~min}$ of moderate to very strenuous intensity for 3-4-year-olds (World Health Organization, 2019). In Germany, daily physical activity levels of at least $60 \mathrm{~min}$ are achieved by no more than $42.5 \%$ of girls and $48.9 \%$ of boys aged 3-6 years (Finger et al., 2018).

Another strong determinant of young children's health is sedentary behavior (Poitras et al., 2017). In times of digitalization and technological change, screen media use is becoming increasingly important in kindergarten children's leisure time (Hinkley et al., 2010; Radesky and Christakis, 2016; Canadian Paediatric Society, 2017). Recommendations on "sedentary screen time" defined as "time spent passively watching screen-based entertainment (TV, computer, mobile devices" (World Health Organization, 2019, p. 5) state that children aged 3-4 years should use screen media for no more than $1 \mathrm{~h}$ per day (World Health Organization, 2019). In Germany, $44 \%$ of $2-5$-year-olds watch television daily in addition to video/DVD or computer/console/online games and the use of smartphones and tablets, resulting in an average of $43 \mathrm{~min}$ per day (Medienpädagogischer Forschungsverbund Südwest, 2014). Longitudinal investigations show that screen media habits such as heavy television use in childhood persist into early adulthood (York, 2016). Therefore, early childhood is an important period for implementing preventive measures to promote a healthy lifestyle including reduced screen media use in order to prevent potential subsequent developments detrimental to health (York, 2016; Canadian Paediatric Society, 2017).

For instance, there is a clear association between children's television viewing of more than $2 \mathrm{~h}$ per day and lower well-being, less self-control and emotional stability (Twenge and Campbell, 2018), decreased fitness (Hardy et al., 2018), lower school and academic performance (Howie et al., 2020; Mineshita et al., 2021), reduced social skills (Hinkley et al., 2010), cardio-vascular diseases (Lissak, 2018) as well as mental and social disorders (Pagani et al., 2016; Stiglic and Viner, 2019).

Yet, regular and sufficient physical activity is associated with favorable metabolic health (Oliveira and Guedes, 2016), healthy body composition and better cardiorespiratory fitness (Füssenich et al., 2015), positive effects on motor skills (Zeng et al., 2017), a reduced likelihood of psychological and cardiometabolic complaints and better cognitive and psychosocial skills (Carson et al., 2017; Biddle et al., 2019; Rodriguez-Ayllon et al., 2019).

Both of those health behaviors are known to be associated with parental education status as well as the family's socioeconomic and migration background (Ball, 2015; Lepeleere et al., 2015; Finger et al., 2018). Parents play an important role in guiding their children's health behaviors in the early years (Wittkowski et al., 2016; Lee et al., 2018). One important component in behavior change is the psychological construct "self-efficacy" (SE) (Bandura, 1997). It is based on social cognitive (learning) theory (Bandura, 1997, 2001) and is defined as "people's beliefs about their capabilities to produce designated levels of performance that exercise influence over events that affect their lives" (Bandura, 1994, p. 2).

SE is dynamic and can be developed by any person (Schunk and Ertmer, 2000). Moreover, it is strongly related to one's own competence and future behavior. However, it is not the actual abilities that are important, but rather confidence in one's own abilities (Bandura, 1977). Solely with the knowledge that one's own abilities are sufficient to show the desired behavior, behavior modification is possible (Bandura, 1977).

General SE, which describes a general, optimistic appraisal of life coping skills, that includes all areas of life, is to be distinguished from SE related to a specific area (Bandura, 1997). Parental self-efficacy (PSE), a specific form of SE, describes the subjective conviction or belief in one's own abilities to be a good parent and influence the child in a way that promotes health and success (Jones and Prinz, 2005; Glatz and Buchanan, 2015; Benedetto and Ingrassia, 2018; Albanese et al., 2019). High PSE is associated with confidence in acquiring and practicing effective parenting skills. Conversely, parents with low PSE find it more difficult to solve challenging parenting situations effectively (Jones and Prinz, 2005). PSE influences parental competence as well as child development and thus contributes to the success of parenting (Jones and Prinz, 2005). Therefore, PSE is thought to have strong effects on child development and health (Albanese et al., 2019).

Due to the multiple ways in which PSE affects children, the construct is gaining increasing attention in child health promotion (Jones and Prinz, 2005; Ekim, 2016; Möhler et al., 2020). Especially physical activity and media use represent two behaviors that could be affected by PSE (Smith et al., 2010). A meta-analysis presented heterogeneous data regarding the relationship of PSE on children's physical activity and screen media use (Xu et al., 2015). Only an Australian cross-sectional study showed that preschool children whose parents reported higher PSE were less likely to undercut the physical activity recommendations of $3 \mathrm{~h}$ per day (Smith et al., 2010). Similarly, a Swedish study showed that maternal SE was associated with higher MVPA (moderate-to-vigorous physical activity) in their 4 -year-old children. Whereas no correlations were seen for light forms of exercise or sedentary behavior (Rohde et al., 2018).

At ages 6 years old and younger, a clear relationship also emerged between PSE and children's screen media behavior (Xu et al., 2015). Preschool children of parents with lower PSE exceeded the recommendation of no more than $2 \mathrm{~h}$ of daily screen media use significantly more often than children of more selfefficacious parents. PSE is thus associated with children's physical activity and screen media behavior (Smith et al., 2010). However, studies have also shown contrary results and suggest a different impact of PSE on physical activity and screen media behavior depending on children's gender when aged 6-12 years (Lepeleere et al., 2015). Since most of those associations increase with age 
(Smith et al., 2010), early health promotion is vital to enhace children's chances for a healthy lifestyle.

This indicates that it is particularly important to identify predictors that increase physical activity behavior and reduce screen media use, thus positively influencing children's health. It has been shown that PSE is an important factor in influencing children's physical activity and screen media use positively. Despite this, some ambiguous relationships still emerge that need to be further examined and elucidated. To the best of our knowledge, there are no studies investigating the influence of PSE on physical activity and screen media use of German kindergarten children; and neither is there a study considering the effect of PSE in terms of success of an intervention. In order to uncover previously unexplored mechanisms of PSE, data of the health promotion program "Join the Healthy Boat" were examined and presented below.

"Join the Healthy Boat" is a health promoting program for (pre-)school children that tries to incorporate all of those aspects mentioned above: physical activity promotion, reduction of screen media use and involvement of parents in order to increase their PSE.

Aim of the current study was therefore to investigate the influence of PSE on kindergarten children's physical activity and screen media behavior. Additionally, it was tested how PSE changes the effect of the health promoting intervention "Join the Healthy Boat" on kindergarten children's physical activity and screen media behavior.

\section{MATERIALS AND METHODS}

\section{Intervention}

The "Intervention Mapping Approach" (IMA) (Bartholomew et al., 2006) was used to design the intervention of "Join the Healthy Boat" (Wartha et al., 2016). Based on a need assessment, concrete program targets were specified. Using theoretical models, such as Bandura's socio-cognitive theory (Bandura, 2001) and Bronfenbrenner's socio-ecological approach (Bronfenbrenner, 1979), concrete applications for health promotion were established and conceptualized. The subsequent implementation in kindergartens and the program's evaluation were planned and carried out based on the above-mentioned framework (Wartha et al., 2016).

Similarly, to the intervention designed for primary schools (Wartha et al., 2017), the key topics of the interventions are increasing physical activity and meaningful leisure time activities including reduced screen media use. A healthy diet is targeted by increasing fruit and vegetable intake as well as reducing sugar sweetened beverage consumption. The materials, which consist of 20 exercise and games lessons as well as 30 ready-to-useideas of various lengths, were designed to be integrated into the daily life of participating kindergartens. Through healthy eating, physical activity and leisure time units, children can explore alternatives for their behavior, gain knowledge about their bodies and health as well as improve their motor skills, physical activity, and healthy eating habits. Additionally, short activity games, which can be used twice daily, were implemented. To also include parents, two parents' nights took place and parental letters were provided in three different languages (Kobel et al., 2017). In order to implement the program in kindergartens sustainably, kindergarten teachers were trained and received the bespoke materials, including instructional behavioral and educational resources free. They then implemented the program throughout 1 year in their kindergarten so children would experience a health-promoting environment, which would make it easier to enhance their health and well-being. On average, children received two units per week in addition to the two daily short activity games.

\section{Study Design and Participants}

The study was designed as a prospective randomized controlled trial with two points of measurement.

All 7,937 kindergartens in South-west Germany were made aware of the intervention program and its evaluation study by mail. Sixty-six kindergartens showed interest in participating in the study. However, four of those had to be excluded due to staffing and organizational reasons. To ensure a similar number of participants between intervention and control group, kindergartens were stratified based on the number of kindergarten children per kindergarten (method of stratification in Kobel et al., 2017).

Initially, 1,012 children from 62 kindergartens planned to participate, equally distributed in the intervention and control groups. Due to further dropouts, 57 kindergartens, 30 in the intervention group and 27 in the control group, $(N=973$ children) took part in baseline measurements.

After the baseline measurements were conducted, all parents received a questionnaire about their child's health and items that depict the family environment. Kindergarten teachers of the intervention group received their training and ready-to-use materials to implement the intervention in the kindergartens. Kindergarten teachers in the control group carried on as usual and received training and materials the year later, after followup measurements were completed in both, intervention and control group.

Therefore, for the present study, 558 kindergarten children from south-west Germany, aged 3-5 years (and later 4-6 years) were examined at two points of measurement and divided into 318 participants in the intervention group and 240 participants in the control group.

The study was registered at the German Register of Clinical Trials (DRKS; DRKS00010089). In addition, the study protocol has been approved by the Ethics Committee and the Ministry of Culture and Education and was carried out according to the Helsinki Declaration. Parents gave their written informed consent for the study, the children their assent on site.

\section{Measures}

Data were collected objectively during a visit at the kindergarten, and subjectively by means of a questionnaire, the parents completed. Physical activity, screen media use and PSE were assessed at baseline and follow-up via a parental questionnaire. Children's physical activity was assessed by their parents using the following question: "On how many days of a normal week is your child physically active for a total of at least $60 \mathrm{~min}$ 
a day so he or she gets out of breath or begins to sweat?". Parents were given a scale from 0 to 7 days of the week to answer the item. The included items for physical activity as well as screen media use were taken from a validated instrument used in a large German study (German Health Interview and Examination Survey for Children and Adolescents [KiGGS]) with 18,000 German children and adolescents (Lange et al., 2014) and validated against assessment by accelerometry (Kahlert and Brand, 2011). The cut-off of $60 \mathrm{~min}$ for determining sufficient physical activity was set on basis of WHO physical activity guidelines (World Health Organization, 2019).

To assess children's screen media behavior, children's average duration of screen media use on a normal day during the week and on the weekend was given by their parents. Parents responded to "On an average weekday, how much time does your child spend doing the following?" and "On an average Saturday/Sunday, how much time does your child spend with the following activities?" on a 7-point Likert scale, ranging from 0 "not at all" to 7 "more than $3 \mathrm{~h}$ " for watching TV/playing video games, using the computer and tablet computer or using a mobile phone/smartphone. For good comparison, the here used questions were also taken out of the KiGGS questionnaire (Lange et al., 2014). One hour was used as cut-off for determining high screen media use, since WHO recommends no more than $1 \mathrm{~h}$ per day (World Health Organization, 2019).

PSE was assessed using a self-assessment on a scale from "strongly disagree" to "strongly agree" (Likert-7) and was adapted from other validated scales (Bohman et al., 2014). With regard to their children's physical activity, parents were asked to rate whether they "manage to ensure that their child gets sufficient physical activity, even if..." for example, "the weather is bad." In addition, PSE related to children's screen media use was assessed with the item "I manage to make sure my child doesn't watch as much TV, even if..." for example "one of his or her favorite shows comes."

Socioeconomic status consisted of parents' highest educational and occupational qualification, parents' highest occupational status and net household income (Lampert et al., 2014). A migration background was defined as "children with at least one parent born in a foreign country or children who were spoken to in a foreign language for the first 3 years or their life" (Settelmeyer and Erbe, 2010; Federal Statistical Office, 2019). Anthropometric measurements were taken during a visit at kindergarten. Body weight and height were measured by trained staff according to ISAK standards (Marfell-Jones et al., 2012) using calibrated and tared body scales (Seca 826, Hamburg) and a portable stadiometer (Seca 217, Hamburg) in the morning.

National percentiles of BMI were used to determine children's weight status (Kromeyer-Hauschild et al., 2001). A child was considered overweight if their BMI percentiles ranged between the 90th and 97th percentile and obese if their percentiles were greater than 97. Further, children whose BMI percentiles were below the 10th percentile were classified as underweight (Kromeyer-Hauschild et al., 2001).

\section{Data Analysis}

To detect significant differences between the two groups, nonparametric Mann-Whitney-U-tests were calculated. Due to the lack of normal distribution, Shapiro-Wilk-test was used to calculate descriptive values. A significance level of $5 \%$ and a confidence interval of $95 \%$ were chosen for all calculations.

In order to ensure groups of equal size and to be able to perform a more robust calculation, the dependent variable "children's physical activity" and "children's screen media use" were dichotomized, respectively. Due to the dichotomization (categorical dependent variable) and in order to calculate and solve multivariate problems, logistic regressions were chosen as the method for inferential statistical analyses. In the case of physical activity, a cut-off value of four days was chosen to ensure sufficient physical activity on most days of a week. To determine children's screen media use, the average time of screen media use during a usual week (including weekdays and weekends) was calculated and dichotomized at the cut-off of $1 \mathrm{~h}$ of screen media use per day (World Health Organization, 2019). For PSE (children's physical activity as well as their screen media use), the average of the six associated items was calculated. The assumption of a similar distribution of the items was checked in advance. All statistical analyses were performed using IBM SPSS Statistics 26 (SPSS Inc., Chicago, IL, US).

\section{RESULTS}

The sample included 558 kindergarten children, 318 (56.99\%) in the intervention group, 240 in the control group. There were no significant differences with regards to age, height, weight, BMI percentiles, weight status, migration background and low socio-economic status between the two groups. Yet, there were significantly more boys in the intervention group, compared to the control group (Table $\mathbf{1}$ ).

There were no significant changes between baseline and follow-up regarding children's physical activity in intervention or control group. In the intervention group, the proportion of children achieving the WHO physical activity recommendations (World Health Organization, 2019) on 4 days or more per week increased slightly from baseline to follow-up (30.2 vs. $31.1 \%$ for baseline and follow-up, respectively), whereas in the control group the number decreased slightly (26.2 vs. $22.6 \%$ for baseline and follow-up, respectively). Children in the intervention group were active for $2.72(S D=2.02)$ days per week at baseline and for $3.09(S D=2.11)$ days per week at follow-up, while in the control group children were active on $2.57(S D=2.03)$ and $2.50(S D=$ 1.90) days per week, respectively.

Similarly, there were no significant changes in children's screen media use between baseline and follow-up, neither in intervention nor control group. In the intervention group $49.8 \%$ of children used screen media for $<1 \mathrm{~h}$ per day at baseline; at follow-up this decreased to $43.7 \%$ of children. Similar changes were observed in the control group with $51.4 \%$ of children using screen media for $<1 \mathrm{~h}$ per day at baseline and $48.8 \%$ of children at follow-up.

At baseline, PSE regarding children's physical activity differed significantly between intervention and control group [5.14 (SD $=$ $1.45)$ and $4.83(S D=1.51)$ points out of seven possible points for intervention and control group, respectively; $U=23176.00, p=$ $0.023, r=0.11$ ]. This remained virtually the same at follow-up 
TABLE 1 | Sample description baseline (children with participation at baseline and follow-up).

\begin{tabular}{|c|c|c|c|c|}
\hline Characteristic & Missing values & $\begin{array}{l}\text { Intervention } \\
\qquad(N=318)\end{array}$ & $\begin{array}{l}\text { Control } \\
(N=240)\end{array}$ & $\begin{array}{c}\text { Total } \\
(N=558)\end{array}$ \\
\hline Gender* (boys [n; \%]) & 0 & $179(56.29)$ & $113(47.08)$ & $292(52.32)$ \\
\hline Age (years [M; SD]) & 0 & $3.64(0.58)$ & $3.63(0.54)$ & $3.63(0.56)$ \\
\hline Height (cm [M; SD]) & 71 & $105.17(5.73)$ & $105.05(5.54)$ & $105.12(5.65)$ \\
\hline Weight (kg [M; SD]) & 77 & $17.42(2.45)$ & $17.19(2.69)$ & $17.32(2.55)$ \\
\hline BMI percentiles [M; SD] & 77 & $51.90(25.87)$ & $47.91(25.91)$ & $50.27(25.93)$ \\
\hline Overweight (incl. obese) ${ }^{\mathrm{a}}[\mathrm{n} ; \%]$ & 77 & $18(6.30)$ & $10(5.10)$ & $28(5.80)$ \\
\hline Migration background ${ }^{\mathrm{b}}[n ; \%]$ & 116 & $79(31.90)$ & $73(37.60)$ & $152(33.40)$ \\
\hline Low socio-economic status [n; \%] & 222 & $29(15.50)$ & $30(20.10)$ & $59(17.56)$ \\
\hline
\end{tabular}

$M(S D)$ : mean (standard deviation).

*Significant difference between control and intervention group, $X^{2}{ }_{(1)}=4,285, p=0.04$.

a >90th BMI percentile (Kromeyer-Hauschild et al., 2001).

${ }^{b}$ Children with at least one parent born in a foreign country or children who were spoken to in a foreign language for the first 3 years or their life.

with an average of $5.19(S D=1.38)$ in intervention and $4.95(S D$ $=1.36)$ in control group $(U=16744.00, p=0.043, r=0.10)$.

For PSE in relation to screen media behavior, similar values were found, but no significant group differences. At baseline, PSE regarding children's screen media use was $5.45(S D=1.45)$ and $5.34(S D=1.48)$ out of seven possible points for intervention and control group, respectively. At follow-up, this increased slightly to $5.36(S D=1.44)$ and $5.45(S D=1.43)$ for intervention and control group, respectively.

\section{Parental Self-Efficacy as Predictor of Children's Physical Activity}

PSE at baseline was a significant predictor for children's physical activity at follow-up ( $B=0.33, p=0.025$, Table 2$)$. If PSE was increased by one unit at baseline, the odds of higher levels of children's physical activity increased by $39.00 \%$ at follow-up (95\% CI: 1.04-1.86). If evaluated gender-specifically, the effect remained significant for girls only (girls: $B=0.82, p=0.031$; boys: $B=0.24, p=0.186$ ).

The final regression model also revealed children's physical activity at baseline and their gender as significant variables on children's physical activity at follow-up (Table 2).

\section{Parental Self-Efficacy as Moderator Between the Intervention "Join the Healthy Boat" and Children's Physical Activity}

Gender was found to have a significant effect on children's physical activity at follow-up, but no interaction effect of PSE at baseline and intervention effect (change of the children's physical activity from baseline to follow-up) could be found (Figure 1).

\section{Parental Self-Efficacy as Predictor of Children's Screen Media Use}

PSE at baseline was a significant predictor of children's screen media use at follow-up $(B=0.42, p=0.006$; Table 3). If PSE at baseline was increased by one unit, the odds for greater screen media use of their children at follow-up increased by $52.9 \%$ (95\% CI: 1.13-2.07). However, if evaluated gender-specifically, the effect was significant for girls only (girls: $B=0.98, p=0.001$; boys: $B=0.10, p=0.619)$. Children's screen media use at baseline also predicted their screen media use at follow-up strongly and significantly (Table 3).

\section{Parental Self-Efficacy as Moderator Between the Intervention "Join the Healthy Boat" and Children's Screen Media Use}

The model as a whole including all predictors was significant $\left[X^{2}{ }_{(8)}=69.57, p<0.001, n=190\right.$, Figure 2 ), but no significant interaction effect ( $X$ in Figure 2 ) could be observed. Therefore, even for children with more self-efficacious parents, the intervention effect (reduction of child's screen media use from baseline to follow-up) is not enhanced. PSE at baseline showed a significant effect on children's screen media use at follow-up. If PSE at baseline was increased by one unit, the probability that children used screen media for $<1$ h per day at follow-up increased by $79.6 \%$ (95\% CI: 1.08-2.67; Figure 2).

\section{DISCUSSION}

This study investigated the influence of parental self-efficacy on children's physical activity and media behavior in a statewide sample of kindergarten children in Germany within 1 year in intervention and control group of a health promoting intervention. In addition, it was assessed whether PSE would change the effect of the intervention of the health promotion program "Join the Healthy Boat" on children's physical activity and children's screen media use. The results of PSE as a construct that can possibly enhance children's physical activity behaviors showed a significant positive effect of PSE on children's physical activity as well as on children's screen media behavior, especially that of girls.

\section{Parental Self-Efficacy as Predictor of Children's Physical Activity}

The here found significant influence of PSE related to physical activity of kindergarten children is partly consistent with previous literature, which showed that toddlers of more selfefficacious parents moved significantly more in their daily lives 
TABLE 2 | Parental self-efficacy at baseline as predictor of children's physical activity at follow-up.

\begin{tabular}{|c|c|c|c|c|c|}
\hline Predictor & $B$ & $S E$ & $p$ & $\operatorname{Exp}(B)$ & $95 \% \mathrm{Cl}$ for $\operatorname{Exp}(B)$ \\
\hline Constant & -5.47 & 1.82 & 0.003 & 0.04 & \\
\hline PSE $(B)^{a}$ & 0.33 & 0.15 & 0.025 & 1.39 & {$[1.04-1.86]$} \\
\hline Gender & -0.93 & 0.40 & 0.021 & 0.40 & {$[0.18-0.87]$} \\
\hline Age & 0.53 & 0.34 & 0.124 & 1.69 & [0.87-3.31] \\
\hline SES ${ }^{d}$ & 0.04 & 0.33 & 0.897 & 0.00 & {$[0.55-1.98]$} \\
\hline
\end{tabular}

$X^{2}(7)=40.32, p<0.001$, Model fit: Cox and Snell $R^{2}=0.18$, Nagelkerke's $R^{2}=0.27$.

${ }^{a}$ Parental self-efficacy at baseline.

${ }^{b}$ Children's physical activity at baseline.

${ }^{c}$ Children with at least one parent born in a foreign country or children who were spoken to in a foreign language for the first 3 years or their life.

${ }^{d}$ Socio-economic status (parents' highest educational/occupational qualification, parents' highest occupational status and net household income).

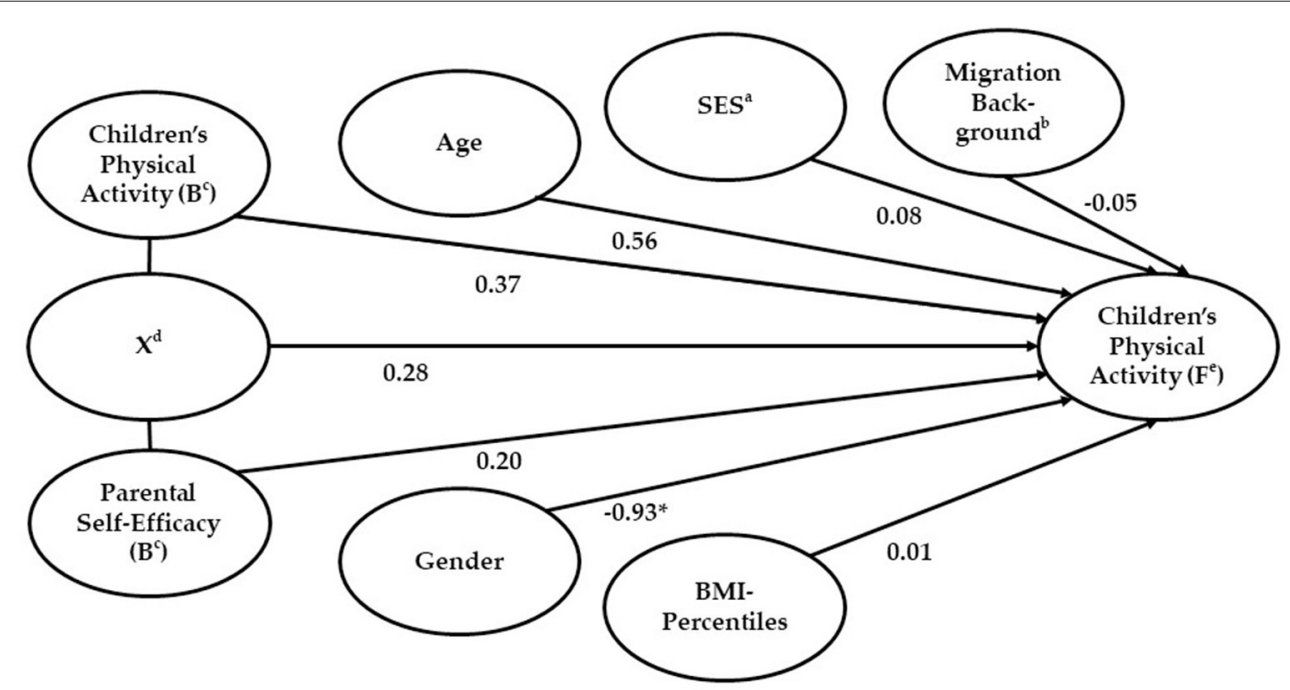

FIGURE 1 | Parental self-efficacy at baseline as predictor of the intervention effect on children's physical activity. Results of the final model with all predictors (203 cases included $\left[X^{2}{ }_{(8)}=41.17, p<0.001\right.$, Model fit: Cox and Snell $R^{2}=0.18$, Nagelkerke's $\left.R^{2}=0.28\right)$. Statistics are standardized regression coefficients. Lines represent relations. ${ }^{*} p<0.05$. 'Socio-economic status (parents' highest educational/occupational qualification, parents' highest occupational status and net household income). ${ }^{b}$ Children with at least one parent born in a foreign country or children who were spoken to in a foreign language for the first 3 years or their life. ${ }^{\mathrm{c}} \mathrm{B}$, baseline. ${ }^{\mathrm{d} X} \mathrm{X}$, interaction effect. ${ }^{\mathrm{e}} \mathrm{F}$, follow-up.

than children of parents with lower SE (Bohman et al., 2014, Smith et al., 2010, Xu et al., 2015). However, there are also studies which did not report such associations (Heerman et al., 2017, Parekh et al., 2018). Yet, in those studies, different statistical analysis methods were used and children's physical activity was assessed objectively. Since in this study children's physical activity was recorded by parental reports and their socio-economic backgrounds differed significantly from those of the before mentioned sample (Heerman et al., 2017), these could be reasons for the different outcomes.

However, if analyzed with a gender context, it was seen that primarily girls benefit from PSE with regards to their physical activity. The significant positive effect of PSE on children's physical activity was lost for boys but strong for girls. It is wellknown that boys are generally more physically active (Foweather et al., 2015; Nilsen et al., 2019), but these results suggest that parents, especially those with high PSE, have great potential to affect their girls' physical activity behaviors.

Apart from PSE, children's physical activity behavior at baseline was a significant predictor for their activity behavior 1 year later-independent of control or intervention group and PSE. Therefore, this was adjusted for in all analyses in order to control for a possible intervention effect.

Interventions have been known to affect results with PSE effects disappearing after controlling for intervention effects (Xu et al., 2014). In the present study, even after controlling 
TABLE 3 | Parental self-efficacy at baseline as predictor of children's screen media use at follow-up.

\begin{tabular}{|c|c|c|c|c|c|}
\hline Predictor & $B$ & $S E$ & $p$ & $\operatorname{Exp}(B)$ & $95 \% \mathrm{Cl}$ for $\operatorname{Exp}(B)$ \\
\hline Constant & -2.94 & 1.81 & 0.105 & 0.05 & \\
\hline PSE (B) ${ }^{a}$ & 0.42 & 0.16 & 0.006 & 1.53 & [1.13-2.07] \\
\hline Gender & 0.54 & 0.36 & 0.138 & 1.71 & [0.84-3.51] \\
\hline Age & -0.29 & 0.33 & 0.373 & 0.75 & [0.39-1.42] \\
\hline SES ${ }^{c}$ & -0.19 & 0.33 & 0.571 & 0.83 & [0.43-1.59] \\
\hline
\end{tabular}

$X^{2}{ }_{(7)}=69.17, p<0.001$, Cox and Snell $R^{2}=0.31$, Nagelkerke's $R^{2}=0.41$

${ }^{a}$ Parental self-efficacy at baseline (B).

${ }^{b}$ Children with at least one parent born in a foreign country or children who were spoken to in a foreign language for the first 3 years or their life.

'Socio-economic status (parents' highest educational/occupational qualification, parents' highest occupational status and net household income).

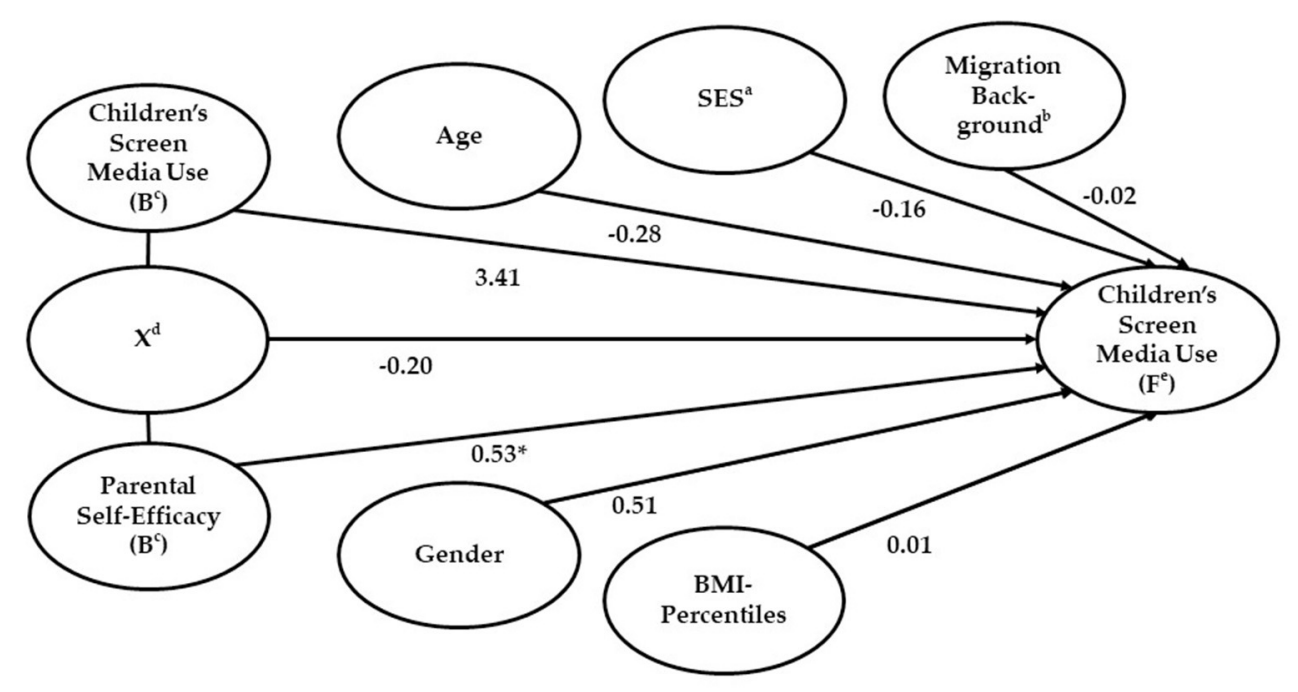

FIGURE 2 | Parental self-efficacy as moderator between the intervention "Join the Healthy Boat" and children's screen media use. Results of the final model with all predictors (190 cases included; $X^{2}{ }_{(8)}=69.57, p<0.001$, model fit: Cox and Snell $R X^{2}=0.31$, Nagelkerke's $R^{2}=0.41$ ). Statistics are standardized regression coefficients. Lines represent relations. ${ }^{*} p<0.05$. 'Socio-economic status (parents' highest educational/occupational qualification, parents' highest occupational status, and net household income). ${ }^{b}$ Children with at least one parent born in a foreign country or children who were spoken to in a foreign language for the first 3 years or their life. ${ }^{\mathrm{C}} \mathrm{B}$, baseline. ${ }^{\mathrm{d} X} \mathrm{X}$, interaction effect. ${ }^{\mathrm{e}} \mathrm{F}$, follow-up.

for a possible intervention effect, a significant effect of PSE on children's physical activity behavior was recorded. Again, assessment methods vary between studies, for instance the selected self-efficacy scale. Xu et al. (2014) for example used items of global PSE in order to assess the effect of PSE on children's physical activity; in this study, specific ones addressing different aspects and situations of physical activity were used. According to Bandura (2006), SE can vary greatly between different domains. Therefore, a lack of specificity could potentially account for missing effects. Further, in order to assess PSE (in contrast to maternal SE or paternal SE) this study assessed PSE by questioning mothers and fathers about the same situations and physical activity aspects whereas other studies focused primarily on maternal SE and therefore assessed mothers' SE (Xu et al., 2014), which may lead to the difference in outcomes.

\section{PSE as Moderator Between the Intervention and Children's Physical Activity}

In the present study, PSE was found to be a significantly positive predictor of children's physical activity at follow-up. Prior to the intervention, it was assumed PSE would have a moderating effect on health promoting aspects, such as physical activity promotion, reduction of sedentary time and screen media use, and therefore on its intervention effects. However, no moderating effect of PSE related to the intervention effect of "Join the Healthy Boat" on children's physical activity was found after 1 year of intervention. Therefore, although children's physical activity was significantly affected by PSE. The increase in physical activity from baseline to follow-up was more likely due to the intervention's key topics and 
materials rather than being moderated by PSE. PSE was hoped to be affected by introducing parental letters, parents' nights and so-called family homework, which all offered action alternatives in order to increase PSE and offer ideas and choices to increase children's physical activity.

\section{Parental Self-Efficacy as Predictor of Children's Screen Media Use}

Not only was PSE a significant positive predictor for children's physical activity behavior; in this study, it was also significantly associated to children's screen media use. Similar results have been shown previously when investigating PSE and children's screen media behavior (Smith et al., 2010; Jago et al., 2015; Downing et al., 2017; Paudel et al., 2017). Yet, depending on age group and analyses, different outcomes have been reported. In 2-year-olds no association of PSE and children's screen media was found (Xu et al., 2014); again, possibly due to the assessment of global PSE among mothers instead of specific PSE related to children's screen media behavior reported by both parents as in this study. It was suggested that specific parental PSE related to children's screen media behavior would produce stronger associations on the reduction of screen time among kindergarten children (Bandura, 2006).

In the context of children's screen media use, their socioeconomic background as well as parental weight status have been shown to be associated to children's screen media behavior. Previous research showed significant effects of PSE on children's screen media use only among normal-weight parents of young children and those of moderate to high socio-economic status (Lepeleere et al., 2015). In the present study, those effects could be confirmed for the same age group and was controlled for the socio-economic status (as well as migration background). Parental weight status was not considered here. Possibly, the role of parental weight status should be included in future studies to further investigate its influence and parental perception on children's (health) behaviors.

As seen for children's physical activity, in this study, PSE was primarily a positive predictor of screen media behaviors in girls. This is something not been observed or at least not been reported previously for preschoolers (Lepeleere et al., 2015; Downing et al., 2017); for girls in grade 6 to 10 a significant difference in PSE on screen media use was seen before (Smith et al., 2010). However, this seems to suggest, that gender-specific different effects in younger children should be researched in more depth in future.

\section{PSE as Moderator Between the Intervention and Children's Screen Media Use}

Despite the confirmed predicting effect of PSE on screen media use of kindergarten children in this study and similarly to the analyzed moderating effect of PSE on the intervention "Join the Healthy Boat" on children's physical activity, no moderating effect of PSE related to the intervention effect on children's screen media use was found after 1 year of intervention. Within the intervention, screen media reduction was addressed by lessons delivered by teachers including behavioral contracting and budgeting of screen media use, offering action alternatives for a screen-free leisure time as well as involving and informing parents through parental letters, parents' nights and family homework. Therefore, an attempt to increase PSE in specific "screen media domains" was made but screen media use at follow-up was largely predicted by children's screen media use at baseline and increased slightly within 1 year in control and intervention group (data not shown; Kobel et al., 2019). Possibly, the use of a health information website would have been more helpful or effective. In a previous study, $69 \%$ of parents reported to feel more self-efficacious in reducing at least two risk factors for obesity after using the "Healthy Families, Healthy Kids 2-5" website (Davies et al., 2014). Alternatively, the engagement in a group-based intervention could have helped, which was shown in a systematic review (Wittkowski et al., 2016). Studies that used task-specific measures of PSE recorded medium to large postintervention effect sizes. In contrast, general measures of PSE just observed small to medium effect sizes (Wittkowski et al., 2016). Thus, a gap between recommended health behaviors (World Health Organization, 2019) and parents' actual knowledge could be closed and, in the process, PSE could be strengthened (Wittkowski et al., 2016).

Interventions should generally alter parental cognition, including PSE. This can be achieved by increasing knowledge and skills in a specific area, such as structured physical activity for (kindergarten) children. In the process, changes in the family and children's home environment most likely occur and should lead to healthier behaviors in families' daily lives (Mollborn and Lawrence, 2018). Therefore, the setting kindergarten is particularly suited for health promotion in young children. In "Join the Healthy Boat" parents are involved in the program and can directly transfer the learned content and behavioral changes to the family and child's everyday life. Other programs, such as an eight-week child-obesity intervention (Health Exercise Nutrition for the Really Young [HENRY]) demonstrated increases in PSE, in addition to increased physical activity and reduced screen time for children (Willis et al., 2014; Bridge et al., 2019).

PSE is emerging as a relevant factor that should also receive more attention from policymakers as well as health providers and health insurers. An increased offer of trainings in this area should be promoted especially with low-threshold possibilities. In order to save resources and reach parents as widely as possible, online interventions are a good complement to face-to-face services. Notwithstanding, it should be taken into account that research on PSE related to children's physical activity and screen media behavior still has gaps. Due to the partially heterogeneous data, the influence of PSE on children's physical activity and screen media behavior should be further elucidated. Nevertheless, the results of this study show clear directions for future research. In addition, the analysis of the effect of PSE on the intervention effect turned out to be novel. Future studies should examine a possible interacting effect, determining factors that contribute to this interaction.

\section{Strengths and Limitations}

However, no study is without limitations, therefore, the following aspects should be considered when interpreting the here 
described findings. First, subjective assessment with its known biases: children's physical activity and screen media behavior were assessed using validated questions included in the German Health Interview and Examination Survey for Children and Adolescents (KiGGS), which previously assessed health behavior in 18,000 German children and adolescents (Lange et al., 2014). However, both behaviors were assessed subjectively and therefore amongst others prone to recall- and social desirability bias. Second, validation of instruments: for the assessment of PSE, items adapted from Bohman et al. (2014) were used but not validated in prior to its use. Since the completion of this study, some more scales to assess PSE have been developed (e.g., Bohman et al., 2016; Norman et al., 2018, Norman et al., 2021) using very similar items, which were designed according to scientific standards and based on Bandura's recommendations (Bandura, 2006). Third, a potential selection bias: participation was voluntary and it should be kept in mind that this study was conducted mainly on Caucasian, educated, and non-single parents and their children. Therefore, the results offer nongeneralizable conclusions, which should not be applied without restriction to all cultures and socioeconomic groups. Forth, variables not considered: although results were adjusted for many co-variables, some-such as parental weight status-were not included, even though an association would have been possible (Lepeleere et al., 2015).

On the other hand, strengths of this study are the relatively large sample size, which may increase the likelihood of having sufficient power to detect intervention effects and its design as a prospective randomized control trail in a relatively wide area, including urban and rural areas. Next, the selected and used guidelines allow for international comparability and transparency. Lastly, PSE was assessed for specific domains by both parents, which permits an extensive in-depth view on PSE for children's physical activity and screen media behaviors.

\section{CONCLUSION}

The results of this study confirm the positive influence of PSE on children's physical activity and screen media behavior, which emphasizes the importance of the construct for the implementation of health promotion and the preventive benefit for children. This study stands out as, to the best of our knowledge, it is the first to investigate the influence of PSE on physical activity and screen media behavior of kindergarten children based on a German sample.

Physical activity and screen media behavior are important determinants of healthy childhood development and should therefore be promoted from an early age (Katzmarzyk et al., 2015). Health consequences could be partially avoided by predictors that reinforce physical activity as well as reduce media use. If parents feel confident that they can positively influence their children's physical activity and screen media behaviors, their children may exhibit more physical activity and spend less time in front of screens. This insight provides an important basis for future societal, social, and political decisions.
Since a person's SE is not a stable, unchanging personality trait, but dynamic and variable due to situational or individual factors (Bandura, 1997), PSE should be specifically promoted, trained and, if necessary, modified in different settings. In this regard, it is important to educate parents and make them aware of the importance of PSE, preferably before their child is born. PSE is critically involved in the success of parenting. In addition, more self-efficacious parents influence child development more positively (Jones and Prinz, 2005).

There is also an opportunity to provide targeted interventions to improve PSE. This could be elements in larger health promotion programs or as a stand-alone intervention (e.g., Miller-Heyl et al., 1998; Wittkowski et al., 2016; Benedetto and Ingrassia, 2018). Already, some studies specifically confirm the effectiveness of interventions to promote PSE regarding children's physical activity and media behaviors (Jones and Prinz, 2005; Lepeleere et al., 2017).

\section{DATA AVAILABILITY STATEMENT}

The raw data supporting the conclusions of this article will be made available by the authors, without undue reservation.

\section{ETHICS STATEMENT}

The studies involving human participants were reviewed and approved by Ethics committee of Ulm University Application no: $188 / 15$. Written informed consent to participate in this study was provided by the participants' legal guardian/next of kin.

\section{AUTHOR CONTRIBUTIONS}

SK, OW, and JS: conceptualization. KK and SK: methodology, data curation, and writing-original draft preparation. KK: software, formal analysis, and visualization. SK, OP, and KK: validation. SK and OW: investigation. JS: resources and funding acquisition. KK, OW, OP, JS, and SK: writing-review and editing. OP and SK: supervision. SK: project administration. All authors have read and agreed to the published version of the manuscript.

\section{FUNDING}

The health promotion program Join the Healthy Boat and its evaluation study were financed by the Baden-Württemberg Foundation (grant no BWS_1.479.00_2009), which had no role in the design, execution, interpretation, or writing of the study.

\section{ACKNOWLEDGMENTS}

The authors would like to thank all members of the program Join the Healthy Boat for their input, as well as all student assistants who were involved in the performance of measurements, and especially all teachers and families for their participation. 


\section{REFERENCES}

Abarca-Gómez, L., Abdeen, Z. A., Hamid, Z. A., Abu-Rmeileh, N. M., Acosta-Cazares, B., and Acuin, C. (2017). Worldwide trends in bodymass index, underweight, overweight, and obesity from 1975 to 2016: a pooled analysis of 2416 population-based measurement studies in 128.9 million children, adolescents, and adults. Lancet 390, 2627-2642. doi: 10.1016/S0140-6736(17)32129-3

Albanese, A. M., Russo, G. R., and Geller, P. A. (2019). The role of parental self-efficacy in parent and child well-being: a systematic review of associated outcomes. Child Care Health Dev. 45, 333-363. doi: 10.1111/cch.12661

Ball, K. (2015). Traversing myths and mountains: addressing socioeconomic inequities in the promotion of nutrition and physical activity behaviours. Int. J. Behav. Nutr. Phys. Act. 12:142. doi: 10.1186/s12966-015-0303-4

Bandura, A. (1977). Self-efficacy: toward a unifying theory of behavioral change. Psychol. Rev. 84, 191-215. doi: 10.1037/0033-295X.84.2.191

Bandura, A. (1994). "Self-efficacy" in Encyclopedia of Human Behavior, ed. V. S. Ramachaudran (New York, NY: Academic Press), 71-81.

Bandura, A. (1997). Self-Efficacy: The Exercise of Control. New York, NY: W. H. Freeman.

Bandura, A. (2001). Social cognitive theory: an agentic perspective. Annu. Rev. Psychol. 52, 1-26. doi: 10.1146/annurev.psych.52.1.1

Bandura, A. (2006). "Guide for constructing self-efficacy scales" in Self-Efficacy Beliefs of Adolescents, eds. F. Pajares, and T. C. Urdan (Charlotte, NC: Information Age Publishing), 307-337.

Bartholomew, L. K., Parcel, G. S., Kok, G., Gottlieb, N. H., and Fernández, M. E. (2006). An Intervention Mapping Approach. San Francisco, CA: Jossey-Bass.

Benedetto, L., and Ingrassia, M. (2018). "Parental self-efficacy in promoting children care and parenting quality," in Parenting - Empirical Advances and Intervention Resources, eds. L. Benedetto, and M. Ingrassia (Rijeka, HRV: InTech), 31-5.

Biddle, S. J. H., Ciaccioni, S., Thomas, G., and Vergeer, I. (2019). Physical activity and mental health in children and adolescents: an updated review of reviews and an analysis of causality. Psychol. Sport Exerc. 42, 146-155. doi: 10.1016/j.psychsport.2018.08.011

Bohman, B., Nyberg, G., Sundblom, E., and Elinder, L. S. (2014). Validity and reliability of a parental self-efficacy instrument in the healthy school start prevention trial of childhood obesity. Health Educ. Behav. 41, 392-396. doi: $10.1177 / 1090198113515243$

Bohman, B., Rasmussen, F., and Ghaderi, A. (2016). Development and psychometric evaluation of a context-based parental self-efficacy instrument for healthy dietary and physical activity behaviors in preschool children. Int. J. Behav. Nutr. Phys. Act. 13:110. doi: 10.1186/s12966-016-0438-y

Bridge, G. L., Willis, T. A., Evans, C. E. L., Roberts, K. P. J., and Rudolf, M. (2019). The impact of HENRY on parenting and family lifestyle: Exploratory analysis of the mechanisms for change. Child Care Health Dev. 45, 850-860. doi: $10.1111 /$ cch. 12694

Bronfenbrenner, U. (1979). The Ecology of Human Development: Experiments by Nature and Design. Cambridge: Harvard University Press.

Canadian Paediatric Society (2017). Screen time and young children: promoting health and development in a digital world. J. Paediatr. Child Health 22, 461-477. doi: 10.1093/pch/pxx123

Carson, V., Lee, E. Y., Hewitt, L., Jennings, C., Hunter, S., Kuzik, N., et al. (2017). Systematic review of the relationships between physical activity and health indicators in the early years (04 years). BMC Public Health 17:854. doi: 10.1186/s12889-0174981-5

Davies, M. A., Terhorst, L., Nakonechny, A. J., Skukla, N., and El Saadawi, G. (2014). The development and effectiveness of a health information website designed to improve parents' self-efficacy in managing risk for obesity in preschoolers. J. Spec. Pediatr. Nurs. 19, 316-330. doi: 10.1111/jspn.12086

Domingues-Montanari, S. (2017). Clinical and psychological effects of excessive screen time on children. J. Paediatr. Child Health 53, 333-338. doi: 10.1111/jpc.13462

Downing, K. L., Hinkley, T., Salmon, J., Hnatiuk, J. A., and Hesketh, K. D. (2017). Do the correlates of screen time and sedentary time differ in preschool children? BMC Public Health 17:285. doi: 10.1186/s12889-017-4276-x
Ekim, A. (2016). The effect of parents' self-efficacy perception on healthy eating and physical activity behaviors of Turkish preschool children. Compr. Child Adolesc. Nurs. 39, 30-40. doi: 10.3109/01460862.2015.1090500

Federal Statistical Office (2019). Bevölkerung und Erwerbstätigkeit: Bevölkerung mit Migrationshintergrund - Ergebnisse des Mikrozensus 2019. Available online at: https://www.destatis.de/DE/Themen/Gesellschaft-Umwelt/ Bevoelkerung/Migration-Integration/Publikationen/_publikationen-innenmigrationshintergrund.html (accessed April 09, 2021).

Finger, J. D., Varnaccia, G., Borrmann, A., Lange, C., and Mensink, G. B. M. (2018). Körperliche Aktivität von Kindern und Jugendlichen in Deutschland - Querschnittergebnisse aus KiGGS Welle 2 und Trends. J. Health Monit. 3, 24-31. doi: 10.17886/RKI-GBE-2018-006

Foweather, L., Knowles, Z., Ridgers, N. D., O’Dwyer, M. V., Foulkes, J. D., and Stratton, G. (2015). Fundamental movement skills in relation to weekday and weekend physical activity in preschool children. J. Sci. Med. Sport. 18, 691-696. doi: 10.1016/j.jsams.2014.09.014

Füssenich, L. M., Boddy, L. M., Green, D. J., Graves, L. E., Foweather, L., Dagger, R. M., et al. (2015). Physical activity guidelines and cardiovascular risk in children: a cross sectional analysis to determine whether 60 minutes is enough. $B M C$ Public Health 16:67. doi: 10.1186/s12889-016-2708-7

Garrido-Miguel, M., Oliveira, A., Cavero-Redondo, I., Álvarez-Bueno, C., Pozuelo-Carrascosa, D. P., Soriano-Cano, A., et al. (2019). Prevalence of overweight and obesity among European preschool children: a systematic review and meta-regression by food group consumption. Nutrients 11:1698. doi: 10.3390/nu1 1071698

GBD 2015 Obesity Collaborators (2017). Health effects of overweight and obesity in 195 countries over 25 years. N. Engl. J. Med. 377, 13-27. doi: 10.1056/NEJMoa1614362

Geserick, M., Vogel, M., Gausche, R., Lipek, T., Spielau, U., Keller, E., et al. (2018). Acceleration of BMI in early childhood and risk of sustained obesity. N. Engl. J. Med. 379, 1303-1312. doi: 10.1056/NEJMoa1803527

Glatz, T., and Buchanan, C. M. (2015). Change and predictors of change in parental self-efficacy from early to middle adolescence. Dev. Psychol. 51, 1367-1379. doi: $10.1037 / \mathrm{dev} 0000035$

Hardy, L. L., Ding, D., Peralta, L. R., Mihrshahi, S., and Merom, D. (2018). Association between sitting, screen time, fitness domains, and fundamental motor skills in children aged 5-16 years: cross-sectional population study. $J$. Phys. Act. Health 15, 933-940. doi: 10.1123/jpah.2017-0620

Heerman, W. J., Taylor, J. L., Wallston, K. A., and Barkin, S. L. (2017). Parenting self-efficacy, parent depression, and healthy childhood behaviors in a lowincome minority population: a cross-sectional analysis. Matern. Child Health J. 21, 1156-1165. doi: 10.1007/s10995-016-2214-7

Hinkley, T., Salmon, J., Okely, A. D., and Trost, S. G. (2010). Correlates of sedentary behaviours in preschool children: a review. Int. J. Behav. Nutr. Phys. Act. 7:66. doi: 10.1186/1479-5868-7-66

Howie, E. K., Joosten, J., Harris, C. J., and Straker, L. M. (2020). Associations between meeting sleep, physical activity or screen time behaviour guidelines and academic performance in Australian school children. BMC Public Health 20:520. doi: 10.1186/s12889-020-08620-w

Jago, R., Wood, L., Zahra, J., Thompson, J. L., and Sebire, S. J. (2015). Parental control, nurturance, self-efficacy, and screen viewing among 5-to 6-year-old children: A cross-sectional mediation analysis to inform potential behavior change strategies. Child. Obes. 11, 139-147. doi: 10.1089/chi.2014.0110

Jones, T. L., and Prinz, R. J. (2005). Potential roles of parental self-efficacy in parent and child adjustment: A review. Clin. Psychol. Rev. 25, 341-363. doi: 10.1016/j.cpr.2004.12.004

Kahlert, D., and Brand, R. (2011). Comparing self-report and accelerometry data. A contribution to the validation of the MoMo-Physical activity questionnaire for children and adolescents. Dt Z SpoMed. 62, 36-41.

Katzmarzyk, P. T., Barreira, T. V., Broyles, S. T., Champagne, C. M., Chaput, J.P., Fogelholm, M., et al. (2015). Relationship between lifestyle behaviors and obesity in children ages 9-11: Results from a 12-country study. Obesity 23, 1696-1702. doi: 10.1002/oby.21152

Kobel, S., Wartha, O., Lämmle, C., Dreyhaupt, J., and Steinacker, J. M. (2019). Intervention effects of a kindergarten-based health promtion programme on obesity related behvioural outcomes and BMI percentiles. Prev. Med. Rep. 15:100931. doi: 10.1016/j.pmedr.2019.100931 
Kobel, S., Wartha, O., Wirt, T., Dreyhaupt, J., Lämmle, C., Friedemann, E.-M., et al. (2017). Design, implementation, and study protocol of a kindergartenbased health promotion intervention. Biomed. Res. Int. 2017:4347675. doi: $10.1155 / 2017 / 4347675$

Kobes, A., Kretschmer, T., Timmerman, G., and Schreuder, P. (2018). Interventions aimed at preventing and reducing overweight/obesity among children and adolescents: a meta-synthesis. Obesity Rev. 19, 1065-1079. doi: $10.1111 /$ obr.12688

Kromeyer-Hauschild, K., Wabitsch, M., Kunze, D., Geller, F., Gei,B, H. C., Hesse, V., et al. (2001). Perzentile für den Body-Mass-Index für das Kindesund Jugendalter unter Heranziehung verschiedener deutscher Stichproben. Monatsschrift Kinderheilkunde 149, 807-818. doi: 10.1007/s001120170107

Lampert, T., Müters, S., Stolzenberg, H., and Kroll, L. E. (2014). Messung des sozioökonomischen Status in der KiGGS-Studie: Erste Folgebefragung (KiGGS Welle 1). Bundesgesundheitsblatt 57, 762-770. doi: 10.1007/s00103-014-1974-8

Lange, M., Butschalowsky, H. G., Jentsch, F., Kuhnert, R., Schaffrath Rosario, A., Schlaud, M., et al. (2014). Die erste KiGGS-Folgebefragung (KiGGS Welle 1) Studiendurchführung, Stichprobendesign und Response. Bundesgesundheitsblatt 57, 747-761. doi: 10.1007/s00103-014-1973-9

Lee, E.-Y., Hesketh, K. D., Rhodes, R. E., Rinaldi, C. M., Spence, J. C., and Carson, V. (2018). Role of parental and environmental characteristics in toddlers' physical activity and screen time: Bayesian analysis of structural equation models. Int. J. Behav. Nutr. Phys. Act. 15:17. doi: 10.1186/s12966-018-0649-5

Lepeleere, S., de Bourdeaudhuij, I., de Cardon, G., and Verloigne, M. (2015). Do specific parenting practices and related parental selfefficacy associate with physical activity and screen time among primary schoolchildren? A cross-sectional study in Belgium. BMJ Open 5:e00720. doi: 10.1136/bmjopen-2014-007209

Lepeleere, S., de, Bourdeaudhuij, I., de, Cardon, G., and Verloigne, M. (2017). The effect of an online video intervention 'Movie Models' on specific parenting practices and parental self-efficacy related to children's physical activity, screentime and healthy diet: a quasi experimental study. BMC Public Health 17:366. doi: 10.1186/s12889-017-4264-1

Ling, J., Robbins, L. B., and Wen, F. (2016). Interventions to prevent and manage overweight or obesity in preschool children: a systematic review. Int. J. Nurs. Stud. 53, 270-289. doi: 10.1016/j.ijnurstu.2015.10.017

Lissak, G. (2018). Adverse physiological and psychological effects of screen time on children and adolescents: literature review and case study. Environ. Res. 164, 149-157. doi: 10.1016/j.envres.2018.01.015

Llewellyn, A., Simmonds, M., Owen, C. G., and Woolacott, N. (2016). Childhood obesity as a predictor of morbidity in adulthood: a systematic review and meta-analysis. Obes. Rev. 17, 56-67. doi: 10.1111/obr.12316

Marfell-Jones, M. J., Stewart, A. D., and Ridder, J. H., de. (2012). International Standards for Anthropometric Assessment. Wellington: International Society for the Advancement of Kinanthropometry.

Medienpädagogischer Forschungsverbund Südwest (2014). miniKIM 2014 Kleinkinder und Medien: Basisuntersuchung zum Medienumgang 2- bis 5Jähriger in Deutschland. Available online at: https://www.mpfs.de/studien/? tab=tab-18-3 (accessed November 13, 2020).

Medienpädagogischer Forschungsverbund Südwest (2018). KIM-Studie 2018: Basisuntersuchung zum Medienumgang 6- bis 13-Jährige in Deutschland: Kindheit, Internet, Medien. Available online at: https://www.mpfs.de/studien/? tab $=$ tab-18-2 (accessed November 13, 2020).

Miller-Heyl, J., MacPhee, D., and Fritz, J. J. (1998). DARE to be you: a family-support, early prevention program. J. Prim. Prev. 18, 257-285. doi: 10.1023/A:1024602927381

Mineshita, Y., Kim, H. K., Chijiki, H., Nanba, T., Shinto, T., Furuhashi, S., et al. (2021). Screen time duration and timing: effects on obesity, physical activity, dry eyes, and learning ability in elementary school children. BMC Public Health 21:422. doi: 10.1186/s12889-021-10484-7

Möhler, R., Wartha, O., Steinacker, J. M., Szagun, B., and Kobel, S. (2020). Parental self-efficacy as a predictor of children's nutrition and the potential mediator effect between the health promotion program "join the healthy boat" and children's nutrition. Int. J. Environ. Res. Public Health 17:9463. doi: 10.3390/ijerph17249463

Mollborn, S., and Lawrence, E. (2018). Family, peer, and school influences on children's developing healthy lifestyles. J. Health Soc. Behav. 59, 133-150. doi: $10.1177 / 0022146517750637$
Nilsen, A. K. O., Anderssen, S. A., Ylvisaaker, E., Johannessen, K., and Aadland, E. (2019). Physical activity among Norwegian preschoolers varies by sex, age, and season. Scand. J. Med. Sci. Sports 29, 862-873. doi: 10.1111/sms.13405

Norman, Å., Bohman, B., Nyberg, G., and Schäfer Elinder, L. (2018). Psychometric properties of a scale to assess parental self-efficacy for influencing children's dietary, physical activity, sedentary, and screen time behaviors in disadvantaged areas. Health Educ. Behav. 45, 132-140. doi: 10.1177/1090198117699506

Norman, A., Wright, J., and Patterson, E. (2021). Brief parental self-efficacy scales for promoting healthy eating and physical activity in children: a validation study. BMC Public Health. 21:540. doi: 10.1186/s12889-021-10581-7

Oliveira, R. G. D., and Guedes, D. P. (2016). Physical activity, sedentary behavior, cardiorespiratory fitness and metabolic syndrome in adolescents: systematic review and meta-analysis of observational evidence. PLoS One 11:e0168503. doi: 10.1371/journal.pone.0168503

Pagani, L. S., Lévesque-Seck, F., and Fitzpatrick, C. (2016). Prospective associations between televiewing at toddlerhood and later self-reported social impairment at middle school in a Canadian longitudinal cohort born in 1997/1998. Psychol. Med. 46, 3329-3337. doi: 10.1017/S0033291716001689

Parekh, N., Henriksson, P., Delisle Nyström, C., Silfvernagel, K., Ruiz, J. R., Ortega, F. B., et al. (2018). Associations of parental self-efficacy with diet, physical activity, body composition, and cardiorespiratory fitness in Swedish preschoolers: results from the MINISTOP trial. Health Educ. Behav. 45, 238-246. doi: 10.1177/1090198117714019

Paudel, S., Jancey, J., Subedi, N., and Leavy, J. (2017). Correlates of mobile screen media use among children aged 0-8: a systematic review. BMJ Open 7:e014585 doi: 10.1136/bmjopen-2016-014585

Poitras, V. J., Gray, C. E., Janssen, X., Aubert, S., Carson, V., Faulkner, G., et al. (2017). Systematic review of the relationships between sedentary behaviour and health indicators in the early years (0-4 years). BMC Public Health 17:868. doi: 10.1186/s12889-017-4849-8

Radesky, J. S., and Christakis, D. A. (2016). Increased screen time: implications for early childhood development and behavior. Pediatr. Clin. N. Am. 63, 827-839. doi: 10.1016/j.pcl.2016.06.006

Rodriguez-Ayllon, M., Cadenas-Sánchez, C., Estévez-López, F., Muñoz, N. E., Mora-Gonzalez, J., Migueles, J. H., et al. (2019). Role of physical activity and sedentary behavior in the mental health of preschoolers, children and adolescents: a systematic review and meta-analysis. Sports Med. 49, 1383-1410. doi: 10.1007/s40279-019-01099-5

Rohde, J. F., Bohman, B., Berglind, D., Hansson, L. M., Frederiksen, P., Mortensen, E. L., et al. (2018). Cross-sectional associations between maternal self-efficacy and dietary intake and physical activity in four-year-old children of first-time Swedish mothers. Appetite 125, 131-138. doi: 10.1016/j.appet.2018.01.026

Sagar, R., and Gupta, T. (2018). Psychological aspects of obesity in children and adolescents. Indian J. Pediatr. 85, 554-559. doi: 10.1007/s12098-017-2539-2

Saunders, T. J., and Vallance, J. K. (2017). Screen time and health indicators among children and youth: current evidence, limitations and future directions. Appl. Health Econ. Health Policy 15, 323-331. doi: 10.1007/s40258-016-0289-3

Schunk, D. H., and Ertmer, P. A. (2000). "Self-regulation and academic learning: self-efficacy enhancing interventions," in Handbook of Self-Regulation, eds. M. Boekaerts, P. R. Pintrich, and M. Zeidner (New York, NY: Academic Press), 631-649.

Settelmeyer, A., and Erbe, J. (2010). Migrationshintergrund. Zur Operationalisierung des Begriffs in der Berufsbildungsforschung. Schriftenreihe des Bundesinstituts für Berufsbildung Bonn. Available online at: https:// www.bibb.de/dokumente/pdf/wd_112_migrationshintergrund.pdf (accessed February 27, 2021).

Skinner, A. C., Perrin, E. M., Moss, L. A., and Skelton, J. A. (2015). Cardiometabolic risks and severity of obesity in children and young adults. N. Engl. J. Med. 373, 1307-1317. doi: 10.1056/NEJMoa1502821

Smith, B. J., Grunseit, A., Hardy, L. L., King, L., Wolfenden, L., and Milat, A. (2010). Parental influences on child physical activity and screen viewing time: a population based study. BMC Public Health 10:593. doi: 10.1186/1471-2458-10-593

Stiglic, N., and Viner, R. M. (2019). Effects of screentime on the health and wellbeing of children and adolescents: a systematic review of reviews. BMJ Open 9:e023191. doi: 10.1136/bmjopen-2018-023191

Twenge, J. M., and Campbell, W. K. (2018). Associations between screen time and lower psychological well-being among children and adolescents: 
evidence from a population-based study. Prev. Med. Rep. 12, 271-283. doi: 10.1016/j.pmedr.2018.10.003

Ward, Z. J., Long, M. W., Resch, S. C., Giles, C. M., Cradock, A. L., and Gortmaker, S. L. (2017). Simulation of growth trajectories of childhood obesity into adulthood. N. Engl. J. Med. 377, 2145-2153. doi: 10.1056/NEJMoa1703860

Wartha, O., Kobel, S., Lämmle, O., Mosler, S., and Steinacker, J. M. (2016). Entwicklung eines settingspezifischen Gesundheitsförderprogramms durch die Verwendung des Intervention-Mapping-Ansatzes: "Komm mit in das gesunde Boot - Kindergarten". Präv. Gesundheitsförderung 11, 65-72. doi: $10.1007 / \mathrm{s} 11553-016-0531-8$

Wartha, O., Lämmle, C., Kobel, S., Wirt, T., and Steinacker, J. M. (2017). Aufbau des Bewegungsmoduls des schulbasierten Gesundheitsförderprogramms "Komm mit in das gesunde Boot". Dtsch. Z. Sportmed. 68, 20-26. doi: $10.5960 / \mathrm{dzsm} .2016 .265$

Willis, T. A., George, J., Hunt, C., Roberts, K. P. J., Evans, C. E. L., Brown, R. E., et al. (2014). Combating child obesity: impact of HENRY on parenting and family lifestyle. Pediatr. Obes. 9, 339-350. doi: 10.1111/j.2047-6310.2013.00183.x

Wittkowski, A., Dowling, H., and Smith, D. M. (2016). Does engaging in a group-based intervention increase parental self-efficacy in parents of preschool children? A systematic review of the current literature. J. Child Fam. Stud. 25, 3173-3191. doi: 10.1007/s10826-016-0464-z

World Health Organization (2019). Guidelines on Physical Activity, Sedentary Behaviour and Sleep for Children Under 5 Years of Age. Available online at: https://www.who.int/publications/i/item/9789241550536 (accessed April 09, 2021).

Xu, H., Wen, L. M., and Rissel, C. (2014). Associations of maternal influences with outdoor play and screen time of two-year-olds: findings from the healthy beginnings trial. J. Paediatr. Child Health 50, 680-686. doi: 10.1111/jpc.12604
Xu, H., Wen, L. M., and Rissel, C. (2015). Associations of parental influences with physical activity and screen time among young children: a systematic review. J. Obes. 2015" 546925. doi: 10.1155/2015/546925

York, C. (2016). Heavy childhood television use persists into young adulthood and is associated with increased BMI. Obesity 24, 924-928. doi: $10.1002 /$ oby.21453

Zeng, N., Ayyub, M., Sun, H., Wen, X., Xiang, P., and Gao, Z. (2017). Effects of physical activity on motor skills and cognitive development in early childhood: a systematic review. Biomed Res. Int. 2017:2760716. doi: 10.1155/2017/ 2760716

Conflict of Interest: The authors declare that the research was conducted in the absence of any commercial or financial relationships that could be construed as a potential conflict of interest.

Publisher's Note: All claims expressed in this article are solely those of the authors and do not necessarily represent those of their affiliated organizations, or those of the publisher, the editors and the reviewers. Any product that may be evaluated in this article, or claim that may be made by its manufacturer, is not guaranteed or endorsed by the publisher.

Copyright (๑) 2021 Kieslinger, Wartha, Pollatos, Steinacker and Kobel. This is an open-access article distributed under the terms of the Creative Commons Attribution License (CC BY). The use, distribution or reproduction in other forums is permitted, provided the original author(s) and the copyright owner(s) are credited and that the original publication in this journal is cited, in accordance with accepted academic practice. No use, distribution or reproduction is permitted which does not comply with these terms. 